\title{
How treatments with endocrine and metabolic drugs influence pituitary cell function
}

\author{
Giovanni Tulipano \\ Unit of Pharmacology, Department of Molecular and Translational Medicine, University of Brescia, Brescia, Italy
}

Correspondence should be addressed to G Tulipano: giovanni.tulipano@unibs.it

\begin{abstract}
A variety of endocrine and metabolic signals regulate pituitary cell function acting through the hypothalamus-pituitary neuroendocrine axes or directly at the pituitary level. The underlying intracellular transduction mechanisms in pituitary cells are still debated.

AMP-activated protein kinase (AMPK) functions as a cellular sensor of low energy stores in all mammalian cells and promotes adaptive changes in response to calorie restriction. It is also regarded as a target for therapy of proliferative disorders. Various hormones and drugs can promote tissue-specific activation or inhibition of AMPK by enhancing or inhibiting AMPK phosphorylation, respectively. This review explores the preclinical studies published in the last decade that investigate the role of AMP-activated protein kinase in the intracellular transduction pathways downstream of endocrine and metabolic signals or drugs affecting pituitary cell function, and its role as a target for drug therapy of pituitary proliferative disorders. The effects of the hypoglycemic agent metformin, which is an indirect AMPK activator, are discussed. The multiple effects of metformin on cell metabolism and cell signalling and ultimately on cell function may be either dependent or independent of AMPK. The in vitro effects of metformin may also help highlighting differences in metabolic requirements between pituitary adenomatous cells and normal cells.
\end{abstract}

\section{Introduction}

The pituitary gland is located at the base of the brain and consists of two distinct structures, the anterior pituitary or adenohypophysis and the posterior lobe or neurohypophysis. The activity of the anterior pituitary is characterized by finely regulated synthesis and release of peptide hormones from five distinct cells types: growth hormone $(\mathrm{GH})$ from somatotrophs, prolactin (PRL) from lactotrophs, adrenocorticotropin (ACTH) from corticotrophs, thyrotropin (TSH) from thyrotrophs and follicle-stimulating hormone/luteinizing hormone (FSH/LH) from gonadotrophs. The pituitary hormones act on endocrine and non-endocrine target tissues involved in different physiological functions including somatic growth, reproduction, metabolism, stressrelated responses and homeostatic responses. It is well established that the hypothalamus has a primary role in the control of the anterior pituitary cell function which is ultimately mediated by hypothalamic neuropeptides (hypophysiotropic hormones) released into the capillary bed in the median eminence and transported directly to the pituitary cells via the hypophyseal portal vessels $(1,2)$. The hypothalamus can be regarded as point of integration of central and peripheral signals which contribute to the complex regulation of the neuroendocrine axes activity underlying the physiological secretory patterns of pituitary hormones as well as any physiopathological changes in pituitary function. Actually, there has long been evidence that some peripheral signals act also directly on pituitary cells $(3,4)$. In this regard, it has been recently highlighted the role played by metabolic factors, from endocrine
This work is licensed under a Creative Commons Attribution-NonCommercial-NoDerivatives 4.0 elpternationab bicense.ifica.com at 04/26/2023 12:06:04PM 
signals to metabolic substrates, in the direct regulation of different pituitary cell types like gonadotroph- and somatotroph cells $(4,5,6,7)$. Some of them take part in feedback regulatory loops between the anterior pituitary cells and their target tissues. The crosstalk between the pituitary and peripheral tissues controlling metabolic functions has suggested a new point of view with a focus on pituitary cells as metabolic sensors integrating central and peripheral signals in order to orchestrate homeostatic responses. Finally, it is worth remarking that the actual integration of multiple signals interacting with their own specific receptors expressed by a given pituitary cell type occurs at the level of the intracellular signal transduction pathways.

AMP-activated protein kinase (AMPK, official symbol PRKA) is expressed in all eukaryotic cells and has emerged as a key factor in regulating intermediary metabolism and energy homeostasis by acting as a simple sensor of low energy stores within cells and as a part of complex signal transduction networks mediating the effects of multiple signals in different tissues (8).

AMPK is expressed throughout the brain including areas that are involved in the control of food intake, energy expenditure and neuroendocrine function, such as the hypothalamus and the hindbrain. AMPK is also expressed in the anterior pituitary cells. More in detail, in the hypothalamus, AMPK is highly expressed in the arcuate, dorsomedial, paraventricular and ventromedial nuclei. It is thought to act as a nutrient (i.e. glucose) sensor and to mediate the regulatory effects of hormones (leptin, ghrelin, insulin, adiponectin, GLP-1) on energy homeostasis. In summary, hypothalamic AMPK has a role in integrating peripheral signals with neural circuits, and its activation is related to increased food intake and decreased thermogenesis as adaptive changes to calorie restriction $(9,10,11)$. In the last 10 years, evidence has accumulated that AMPK plays also a role in the interplay between the activity of neuroendocrine axes and energy homeostasis at both hypothalamic and pituitary level. Within this context, the most compelling data regard the influence of energy status on gonadotroph axis activity and fertility via AMPK (5).

Apart from being a direct sensor of energy store within cells and a mediator of endogenous signals, including hormones and inflammatory factors, AMPK is also regulated by drugs currently approved for the treatment of different pathologies, newly developed compounds in drug discovery and natural compounds (i.e. resveratrol) from foods (12).
The purpose of this review is to provide an overview of our current knowledge on the role played by AMPK in the regulation of neuroendocrine axes activity as a downstream mediator of metabolic signals, hormones and drugs affecting pituitary cell function. As to drugs, the effects of the well-known hypoglycemic agent metformin on pituitary cell function will be discussed. Metformin is regarded as an indirect AMPK activator; however, its multiple effects on cell metabolism, cell signalling and ultimately on cell functions are not entirely mediated by AMPK (13). Finally, AMPK regulates cell viability and cell growth and is regarded as a drug discovery target for tumor therapy $(14,15)$. Metformin is currently being investigated for anti-tumor effects in endocrine malignancies (16). The last section of this review explores the results of preclinical studies aimed at investigating the effects of AMPK activation and the effects of metformin on pituitary tumor cells published in the last decade.

\section{AMP-activated protein kinase (AMPK) regulation and activity}

AMPK is expressed in all eukaryotic cells as a heterotrimeric protein. Under conditions that increase cellular AMP levels such as glucose deprivation and hypoxia, AMP binds to the $\gamma$ subunit and allosterically activates the catalytic subunit to fivefold. AMP also facilitates the phosphorylation of threonine-172 in the activation loop within the alpha subunit by the upstream serine/threonine kinase-11 (STK11 or LKB1) and provides protection from dephosphorylation. Phosphorylated AMPK is 100-fold more active than the native protein. Actually, apart from the allosteric regulation, AMPK is involved in a kinase cascade $(8,12,17)$. It has been shown that various growth factors and hormones can promote AMPK activation through its phosphorylation. Reportedly, apart from LKB1, calcium/calmodulin-dependent protein kinase (CAMKK), transforming growth factor-beta-activated kinase (TAK1) and ataxia telangiectasia mutated protein may function as AMPK kinases $(9,12)$.

Activated AMPK phosphorylates enzymes and regulatory proteins involved in metabolic pathways in peripheral tissues and CNS. In this way, AMPK downregulates anabolic pathways like fatty acid-, cholesterol-, glycogen- and protein synthesis and enhances catabolic pathways producing ATP in response to a negative energy balance $(17,18,19,20)$. The actions of AMPK on cell metabolism in multiple tissues makes 
it a regulator of systemic metabolism. At the same time, AMPK also plays a role in the regulation of cell growth and differentiation $(15,21,22,23,24,25)$. AMPK activation may cause opposite effects in different cell types. In detail, AMPK has the potential to counteract growth-stimulatory signalling mediated by the activation of mammalian target of rapamycin (mTOR) downstream of growth factor receptors in normal and tumor cells. On the other hand, it may also act as a metabolic survival factor in distinct tumor types (26). Furthermore, AMPK has been shown to affect the signalling pathway mediated by the cAMP-dependent protein kinase (PKA) activation and cAMP-responsive element-binding protein (CREB) phosphorylation in different cell types $(12,27)$. In hepatocytes, biguanides suppress CREB phosphorylation by decreasing the production of cAMP and their effect is mediated by $\operatorname{AMPK}(28,29)$. On the other hand, in rat skeletal muscle cells, AMPK has been shown to phosphorylate transcription factors of the CREB family at the same site as PKA (30). In the CNS, genetic evidence suggests that AMPK is involved in the control of immediate early genes expression upon synaptic activation mediated by the PKA/CREB signalling pathway (31). As to pituitary cells, available data are limited to the effects of metformin in rat pituitary GH/PRL-secreting tumor cells. Metformin tended to cause a moderate increase in phospho-CREB levels without altering the adenylyl cyclase (AC) activity and the cell response to stimuli like forskolin or GHRH. These data suggest a PKA-independent enhancement of CREB phosphorylation by the biguanide (27).

\section{Gonadotroph cell function}

Body energy stores and metabolic status have a clear impact on an energy demanding function such as reproduction. Ensuring sufficient fuel storage and food availability is critical to face the changes related to the attainment of reproductive maturation and for the maintenance of fertility in adulthood. For these reasons, metabolic factors and endocrine signals related to systemic energy status (i.e. insulin, leptin, adiponectin, and ghrelin) exert a pivotal role in the control of the hypothalamic-pituitary-gonadal axis activity, acting at multiple levels (32). The hypothalamus has long been regarded as the main point of integration between signals involved in energy homeostasis and regulation of reproductive function. Gonadotropin-releasing hormone (GnRH) is synthetized mainly in the hypothalamic preoptic area and is the ultimate regulator of gonadotropin release from pituitary $(32,33)$. Kisspeptin is an upstream hypothalamic signal regulating GnRH release $(34,35,36$, 37). Kisspeptin is the product of Kiss1 gene and plays a central role in the timing of puberty and in mediating the modulatory effects of numerous puberty-regulating signals. Kisspeptin neurons are located in the arcuate and in the anteroventral-periventricular nucleus and make direct contact with GnRH neurons. Kisspeptin neurons located in the arcuate nucleus are believed to play a crucial role in determining the pattern of GnRH release related to puberty onset and maintenance of reproductive function in adulthood $(38,39)$. A direct control of $\mathrm{GnRH}$ neurons and Kisspeptin neurons by endocrine signals which primarily cooperate to energy homeostasis has been questioned in recent years and evidence has been accumulated that their action is mediated by an upstream neuronal network involving hypothalamic and extrahypothalamic areas (32). Moreover, a direct role of pituitary gonadotroph cells as metabolic sensor has also been highlighted (5). Hence, the integration of signals received at different levels determines the influence of metabolic status on the hypothalamic-pituitary-gonadal axis activity and ultimately on puberty onset and the maintenance of fertility in adulthood. According with the purpose of this review, current knowledge about the role played by AMPK as an intracellular energy sensor and signal transducer at different levels in this hierarchical system underlying gonadotroph cell function will be now summarized.

At the hypothalamic level, kisspeptin neurons in the ARC were found to express AMPK, and the AMPK activation by chronic subnutrition in immature female rats was related to suppress Kiss1 expression. In the same model, overexpression of a constitutively active form of AMPK in the ARC partially delayed puberty onset and decreased LH levels. On the other hand, conditional ablation of the AMPK $\alpha 1$ subunit in the ARC prevented the delay in puberty onset caused by chronic malnutrition (40). These data suggest that hypothalamic AMPK signalling has an important role in mediating the effects of malnutrition on the control of puberty through a repressive AMPK-Kisspeptin pathway. Moreover, they suggest a putative target for pharmacological modulation of puberty timing in some physiopathological conditions. To this end, the effect of AMPK activation in Kisspeptin neurons may help to explain the effects of metformin, which is an indirect AMPK activator, observed in girls at risk for precocious puberty (41) as well as the endocrine and metabolic effects of metformin observed in girls with precocious pubarche (42). 
Neural networks underlying the interplay between food intake and gonadotroph axis function involve AMPK activity in different areas of CNS, including both hypothalamic nuclei and extra-hypothalamic areas. As to the second item, the pharmacological inhibition of AMPK activity in the hindbrain was shown to reverse the inhibition of GnRH expression and LH release caused by short-term food deprivation in ovariectomized rats which were given oestradiol to replicate proestrous stage (43). Hence, the authors concluded that food deprivation can restrain reproductive neuroendocrine outflow by activating hindbrain AMPK in the presence of circulating oestradiol levels consistent with proestrous. In other words, peak oestradiol levels trigger the LH surge and at the same time increase the sensitivity of the gonadotroph axis to the inhibitory effect of food deprivation which is mediated by hindbrain-derived stimuli linked to AMPK activation. In the same work, the pharmacological analysis also showed that the neural networks linking the hindbrain sensor to the GnRH neurons of the rostral pre-optic area involve nitric oxide (NO)-mediated signalling (43).

Over the last decade, some papers have highlighted the role of AMPK in mediating the effects of drugs and of mediators of energy homeostasis at thelevel of gonadotroph cells. Data have been obtained in rat or in mouse pituitary cells. In primary rat pituitary cultures, metformin had no effects on its own but it was able to reduce LH secretion in response to GnRH and FSH secretion in response to both GnRH and activin. Metformin was shown to induce the AMPK-activating phosphorylation and phosphorylation of AMPK downstream targets. The use of a selective AMPK inhibitor and the overexpression of a dominant negative isoform of AMPK clearly showed the involvement of AMPK activation in the previously mentioned action of metformin (44). In summary, although metformin acts at multiple sites that are involved in the regulation of gonadotropin secretion and fertility (i.e. possible targets at hypothalamic level have been previously discussed), metformin-induced activation of AMPK in gonadotroph cells may contribute to some pharmacological effects of metformin, as in the treatment of polycyctic ovarian syndrome (PCOS) (5). Incidentally, in the same work, the authors evidence a differential expression of distinct isoforms of the AMPK catalytic subunit ( $\alpha$ subunit) in the five cell types of the anterior pituitary gland (44).

Metformin is believed to activate AMPK by affecting cell metabolism and causing a decrease of the ATP:AMP ratio with the outcome of allosteric binding of AMP to the AMPK regulatory subunit $\gamma$, which makes AMPK a better substrate for its upstream kinase LKB1 (12). Actually, the evidence that the indirect activation of AMPK in cultured pituitary gonadotroph cells by a drug can significantly alter gonadotropin release and the sensitivity to $\mathrm{GnRH}$ suggests also to consider AMPK as an intracellular target of hormonal signals mediating information about the systemic energy status at the anterior pituitary cells. Indeed, several hormones show tissue-specific effects on AMPK activity mediated by different mechanisms that generally involve the regulation of upstream kinases. In this regard, as to gonadotroph cells, even before the description of the effects of metformin on primary cells, adiponectin was shown to activate AMPK and to inhibit LH synthesis and release in a mouse cell line (L[ק]T2 gonadotropes) (45).

The direct effects of metformin on gonadotroph cell activity achieved further confirmations by more recent investigations in non-human primate pituitary cells in vitro. Actually, the comparison of the data obtained using primate cells with the data obtained using rodent cells seemingly highlights some species-related differences. In detail, metformin affected the basal FSH secretion from primate pituitary cells, but it was not able to reverse the stimulatory effect of GnRH and did not affect LH release (46).

\section{Somatotroph cell function}

The relationships between body composition and GH-secretory patterns is well established and a number of metabolic and endocrine factors have been suggested as being involved in the complex interplay between peripheral tissues like adipose tissue and skeletal muscle, nutrition and GH axis $(3,47,48)$.

Two hypothalamic peptides are regarded as the main regulators of $\mathrm{GH}$ secretion from the anterior pituitary: the stimulatory action of growth-hormone-releasing hormone (GHRH) and the tonic inhibitory activity of somatostatin have been recognized to be responsible of generating a pulsatile pattern of GH secretion (48, 49). In 1999, the endogenous ligand of the orphan G-protein-coupled receptor GHS-R1a was isolated and characterized. GHS-R1a had been first identified as the receptor for synthetic GH-secretagogues. Its endogenous ligand ghrelin is a 28 -amino acid acylated peptide. It was initially isolated from the stomach and then found to be expressed in multiple organs and tissues, including the hypothalamus (50). Circulating levels of ghrelin are decreased by food intake and increased by food 
deprivation $(51,52)$. Ghrelin circulates in two main forms, acylated ghrelin and unacylated ghrelin. Acylated ghrelin is able to increase GH secretion via a direct effect on pituitary somatotrophs and by a stimulatory action on GHRH release joint to a weak inhibitory activity on somatostatin neurons at the hypothalamus (53). Hence, it could cooperate to generate the secretory patterns of GH. Actually, it has been shown that ghrelin-knockout (KO) mouse has no change in size, growth rate, food intake, body composition and behaviour compared to WT littermates (54). Apart from a possible involvement in the control of the $\mathrm{GH}$ axis, there has been a focus on pleiotropic actions of the acylated and unacylated ghrelin forms and of some alternative products of the ghrelin gene (3). Cortistatin is a neuropeptide mainly expressed in the brain cortex. Cortistatin shows high homology with somatostatin and binds to all somatostatin receptor subtypes with high affinity. As expected, in vitro and in vivo studies revealed that the effects of cortistatin on the $\mathrm{GH}$ axis activity basically match the effects of somatostatin. Actually, the two peptides are not merely analogs, becuase cortistatin contains sequence elements which enable its binding to two distinct receptors, Mas-related gene 2 receptor and ghrelin receptor GHS-R1a. In addition to a different tissue distribution pattern, the existence of distinct receptors suggests that some divergent effects of the two neuropeptides are possible. In this regard, the in vitro analysis evidenced a biphasic dose-dependent effect of cortistatin on GH secretion from pituitary cells. The actual relevance of cortistatin in the physiological control of somatotroph cell function with respect to somatostatin needs to be further investigated (55).

Multiple neurotransmitter pathways as well as a variety of hormones and metabolic factors regulate $\mathrm{GH}$ secretion by acting directly on the anterior pituitary and/or affecting the activity of GHRH and somatostatin neurons at the hypothalamus. Neuroendocrine control of the GH axis activity and the interplay with the control of the systemic energy status have been extensively reviewed elsewhere $(3,4,47,48,56)$. Briefly, as to the second item, increased adiposity and overeating have been long related to reduced $\mathrm{GH}$ secretion. The factors which may be responsible for mediating this relationship include glucose, free fatty acid, insulin, ghrelin and adipokines (3). It is well known that an oral glucose load has a rapid and transient inhibitory effect on GH secretion, most likely mediated at the hypothalamic level. Indeed, glucose does not influence $\mathrm{GH}$ release from in vitro cultured pituitary cells $(6,47,48)$. The acute suppression of GH secretion in overeating is likely related to hyperinsulinemia (57).
High levels of insulin have also been demonstrated to reduce $\mathrm{GH}$ response to $\mathrm{GHRH}$ in healthy humans (58). The action of insulin is partially due to direct suppression of somatotroph cell function (59). Whether the effects of acutely elevated insulin levels might help to explain the longer term changes in $\mathrm{GH}$ release in conditions of increased adiposity is still to be ascertained. Free fatty acids (FFAs) also participate in the regulation of pituitary $\mathrm{GH}$ secretion. Indeed, increased FFA levels block GH release provoked by virtually all stimuli. A direct action of FFA on somatotroph cells has been suggested $(3,59)$. As to adipokines, leptin produced by adipocytes controls body weight by restraining food intake and enhancing energy expenditure at the hypothalamic level $(60,61)$. Its receptor is expressed in the arcuate and periventricular hypothalamic nuclei. In distinct experimental animal models, leptin has been associated with an increase of $\mathrm{GH}$ secretion. This effect has been linked to the central effects of leptin at the hypothalamic level $(62,63)$. Actually, also a direct effect on primary pituitary cells has been shown $(7,64)$. Up to now, it has not been possible to relate the neuroendocrine activity of leptin on $\mathrm{GH}$ axis to the changes in $\mathrm{GH}$ secretion observed in obesity. Indeed, simple forms of obesity lead to elevated leptin levels, and a central resistance to its anorectic effect has been postulated in obese humans $(3,65)$. Actually, in rats made obese by high-fat diet, the effect of leptin on $\mathrm{GH}$ mRNA expression in pituitary was found to be preserved (66). Moreover, in humans the GH response to GHRH was found to be related to the degree of adiposity and not to leptin circulating levels themselves (67). The interplay between adiponectin and GH is complex. Adiponectin acts to increase sensitivity of different multiple tissues to insulin, and insulin resistance is associated with decreased adiponectin levels (68). Adiponectin reduces GHRH-enhanced but not ghrelin-enhanced GH release from primary pituitary cells from primates (7). On the other hand, $\mathrm{GH}$ reduces adiponectin secretion from human adipose tissue in vitro, and GH hypersecretion is related to decreased adiponectin levels in humans and in experimental animal transgenic models (69). These data suggest that adiponectin could mediate the metabolic effects of GH on glucose control, as seen in acromegalic patients (3). Finally, among peripheral hormones, a brief review of the role played by glucocorticoids in the regulation of growth hormone secretion is needed. Glucocorticoids are essential for life and have important physiological effects on intermediate metabolism, fluid homeostasis and immune system functions. They are involved in basal homeostasis and stress-related responses.

This work is licensed under a Creative Commons Attribution-NonCommercial-NoDerivatives 4.0 Internationab ticense.ifica. com at 04/26/2023 12:06:04PM 
Glucocorticoids are known to affect the GH axis activity at multiple levels, acting as gene transcription regulators. Glucocorticoids modulate GH secretion by acting at the hypothalamic and pituitary level and can also influence downstream effectors like insulin-like growth factor-1 (IGF-1). For a long time, a model of biphasic dosedependent effects of glucocorticoid on the somatotrophic axis function has been suggested. Glucocorticoids are essential for differentiation of GH-secreting pituitary cells as well as for maintaining GH synthesis and secretion in the pituitary gland after birth. Actually, chronic glucocorticoid excess is well known to suppress GH release by altering the activity of both GHRH and somatostatin neurons (56).

The integration of multiple central and peripheral signals activating their own receptors at the hypothalamic level or directly at the pituitary level may involve a number of intracellular signalling pathways. In recent years, the role played by AMPK and by the PI3K-mTORC1 pathway in making pituitary somatotroph cells a metabolic sensor has been explored.

Within the hypothalamus, AMPK is highly expressed in the arcuate, dorsomedial, paraventricular and ventromedial nuclei and has clearly emerged as a nutrient and glucose sensor. AMPK activity has a role in tuning orexigenic signals during fasting and during refeeding and in mediating the regulatory effects of multiple peripheral hormones (GLP-1, oxyntomodulin, ghrelin, leptin, adiponectin and insulin) on food intake and energy expenditure. In summary, hypothalamic AMPK has a role in integrating peripheral signals with neural circuits, and its high activation is related to increased food intake and decreased thermogenesis as adaptive changes to calorie restriction whereas low activation is related to refeeding and increased energy expenditure $(9,10)$. To our knowledge, no data have been reported on a possible role of hypothalamic AMPK in regulating the activity of GHRHand somatostatin neurons in the context of the interplay between GH axis and energy homeostasis. On the other hand, some years ago, our research group reported on AMPK activation and function in the anterior pituitary and its implications in the control of somatotroph cell activity. We showed that the AMP mimetic compound 5-aminoimidazole-carboxamide ribonucleoside (AICAR) markedly stimulated the phosphorylation of AMPK in dispersed normal rat pituitary cells in vitro, in a timedependent manner. The activation of AMPK was related to a decrease of GH storage and GH secretion. Compound C, a selective AMPK inhibitor, enhanced GH secretion in response to GHRH. AICAR and somatostatin exerted an additive inhibitory effect on GHRH-stimulated GH release. We concluded that AMPK activity has role in the control of GH synthesis and secretion in rat pituitary cells. AMPK can be an intracellular transducer mediating the effects of circulating hormones or metabolic factors on GH-secreting cells (70).

Based on a more recent work addressing the direct effects of biguanides on the expression and secretion of all the anterior pituitary hormones in non-human primate pituitary cells in vitro, metformin significantly reduced GH expression and secretion and was active at micromolar concentrations (46), not so far from the circulating concentrations of metformin related to its therapeutic glucose-lowering effect in humans (16). Since metformin is an indirect AMPK activator, these data may further support the conclusions derived from the previously mentioned data in rat pituitary cells. Actually, it is worth remarking that metformin is believed to exert its pharmacological effects through multiple mechanisms in distinct tissues, including AMPK-dependent and AMPKindependent actions (13). The effects of metformin on AMPK activation in pituitary cells were not investigated in primate cells and, at present, the only available data have been obtained using a rat GH/PRL-secreting tumor cell line. In these cells, as expected, metformin increased AMPK activity as shown by the analysis of AMPK phosphorylation and AMPK-substrate phosphorylation (27). In primate pituitary cells, the authors investigated the involvement of other intracellular signalling pathways in the metformin-induced decrease of GH secretion by using selective pharmacological inhibitors. The blockade of PI3K, mTOR and intracellular $\mathrm{Ca}^{2+}$ mobilization reversed the inhibitory effect of metformin on GH, FSH and ACTH secretion. On the other hand, the blockade of MAPK activity selectively affected the metformin action on the somatotroph function. The analysis with pharmacological blockers supported the conclusion that the activation of the PI3K-mTOR pathway played a role in mediating metformin action on hormone release in pituitary cells (46). This conclusion goes against an involvement of AMPK activation, as AMPK is largely seen as a functional antagonist of mTOR. On the other hand, since AMPK has been described to negatively modulate mTOR activity $(15,17,25,71,72)$, it is also possible that the PI3K-mTOR pathway activation was necessary to observe an AMPK-mediated inhibitory action of metformin in pituitary cells. In summary, the analysis of phosphorylation cascades would help clarifying in-depth the activation of signalling routes following to the exposure of cells to metformin. 
The study by Vazquez-Borrego and coworkers also evidenced some significant effects of metformin on the mRNA levels of key receptors involved in the regulation of hormone secretion: in detail, metformin was seen to increase the expression of somatostatin receptors $\mathrm{SST}_{2}$ and $\mathrm{SST}_{5}$, leptin receptor, insulin- and IGF-1 receptors in primate pituitary cells, whereas it did not alter GnRH receptor and GHRH receptor expression (46). It is worth remarking that insulin receptor and IGF-1 receptor are expected to activate the PI3K-mTOR pathway in response to their ligands $(17,73)$. By coupling the effects of metformin on receptor expression with the signalling routes involved in its action on hormone release, especially the PI3K-mTOR pathway, we might speculate that metformin is able to sensitize the GH-secretory cells to the inhibitory effect of insulin- and the IGF-1-mediated negative feedback on GH release. Actually, further studies are required to prove that an activation of insulin- or IGF1-receptors may really occur in isolated cultured pituitary cells, in the absence of exogenous ligands.

Metformin has long been used as an insulinsensitizing agent for the treatment of patients with type 2 diabetes $(14,74)$. Currently available data on the effects of metformin on somatotroph axis activity in vivo in humans mainly derive from studies in patients showing different pathological conditions. At present, clinical data do not evidence a prevailing inhibitory action of metformin on GH-secreting pituitary cells in vivo. Actually, the complexity related to the pathological conditions which may per se cause alterations of somatotroph function, to the pleiotropic effects of metformin in different tissues and to the duration of treatments, make it difficult to draw final conclusions about a possible direct effect of metformin on pituitary cells in vivo $(75,76)$. The data obtained by using in vitro cultured pituitary cells suggest that the targets of metformin in vivo include the anterior pituitary and, in detail, also the GH-secreting cells.

A final consideration concerns the strategies aimed at preventing or delaying multiple age-related diseases and conditions. According to a consensus related to the discovery and development of safe interventions to increase healthy lifespan published by experts in the biology and genetics of aging (77), the possible pharmacological inteventions believed to be most promising include:

- drugs that inhibit the mTOR-S6K pathway

- drugs that activate AMPK and specific sirtuins

- chronic metformin use
In such context, the effects of these interventions on the GH-IGF-1 axis activity are surely relevant and require further investigations. Indeed, the role of GH in mammalian aging is still actively explored and the agerelated decline of $\mathrm{GH}$ secretion is variously interpreted as one of causes of altered body composition and other negative symptoms of aging or as a mechanism of protection from cancer and age-related chronic diseases (78).

Factors regulating AMPK activity and metformin can affect the GH-IGF-1 axis activity at multiple levels, by interfering with target tissue response to GH and IGF-1 and by altering pituitary cell function (6).

\section{Corticotroph cells}

Few studies have investigated the role of AMPK in the control of ACTH-secreting pituitary cells. In AtT20 mouse corticotroph cells, the AMP analogue AICAR was shown to enhance the expression of the ACTH precursor POMC. The effect of AICAR on POMC gene transcription was completely cancelled by the AMPK inhibitor compound $\mathrm{C}$ or by dominant negative AMPK. The overexpression of constitutively active AMPK mimicked the effect of AICAR. These data suggest that AMPK directly mediates the effects of starvation and subsequent energy depletion on the HPA axis activity at the pituitary level (79).

Adiponectin is regarded as a starvation hormone and, under fasting conditions, stimulates AMPK activity in CNS and peripheral tissues with the outcome of increased food intake and decreased energy expenditure. Adiponectin was shown to activate AMPK signalling in AtT20 cells and to increase basal ACTH release in the same cells as well as in primary pituitary cell cultures, without altering the cell response to CRH. Although the relationship between the AMPK activation and the effect on ACTH secretion was not deeply investigated and confirmed, the study suggests a role of AMPK in mediating also the action of hormones on corticotroph cells in the context of energy homeostasis (80). Actually, it is necessary to remark some discrepancies between currently available studies. The direct AMPK activation by AICAR increased the expression of the ACTH precursor, POMC, whereas adiponectin did not alter gene transcription. The RT-PCR analysis revealed the expression of adiponectin receptors $\mathrm{R} 1$ and R2 in AtT20 cells but they were not localized in ACTHsecreting cells in human pituitary (81). Hence, speciesrelated differences in the effects of adiponectin may be expected. Finally, the drug metformin is believed to cause

This work is licensed under a Creative Commons Attribution-NonCommercial-NoDerivatives 4.0 Internationab ticense.ifica.com at 04/26/2023 12:06:04PM 
some fasting-mimicking modifications of metabolism in different tissues and is an indirect AMPK activator. Metformin was shown to induce quite opposite effects on corticotroph activity as compared with adiponectin and the direct AMPK activator AICAR. In non-human primate cell cultures, metformin reduced basal ACTH secretion without affecting the response to ghrelin and reduced the expression of POMC (46). The multiple actions of metformin which include AMPK-independent actions, in addition to possible species-related differences, may account for these discrepancies. Nevertheless, we might conclude that direct effects of hormonal and metabolic signals mediating an energy depletion condition on pituitary corticotroph cell function are still controversial.

To our knowledge, no data are currently available on the role of AMPK in the control of TSH-secreting and PRLsecreting pituitary cell functions. As to metformin, the drug did not affect both functions in primate pituitary cell cultures (46). There is increasing interest in its effects on PRL release from prolactinoma cells, in the attempt to improve pharmacological treatment options for this kind of tumors $(82,83)$.

\section{Effects of AMPK activators and effects of metformin on pituitary adenoma cells}

For years, AMPK has been considered a possible therapeutic target in different kinds of neoplasia, since it is involved in the regulation of cell metabolism and cell survival in normal and in tumor cells and is known to negatively regulate intracellular signalling downstream of growth factor receptors $(12,15,17,21,22,25)$. The potential of metformin as an anticancer agent has been documented in diabetic patients, since the treatment with metformin has been related to a lower cancer incidence compared to alternative anti-diabetic drugs $(16,84,85)$. Metformin is a biguanide and a well-known, first-choice drug for type 2 diabetic patients. Actually, it has been recognized to exert pleiotropic effects, including a direct antiproliferative activity in some tumors. Metformin is an indirect AMPK activator but it exerts its effects on cellular bioenergetics and intracellular signalling pathways through both AMPK-dependent and AMPK-independent mechanisms (13). It has been generally accepted that metformin primarily alters cellular bioenergetics, but a clear relationship between its primary action within cells and its systemic effects has not been clearly established yet (Fig. 1). Metformin needs to be transported into cells by transporters for cationic compound like organic cation transporters (OCTs). Hence, its accumulation and its effects within cells are dependent on the expression levels of these transporters at the cell surface. Metformin is believed to indirectly activate AMP-activated protein kinase (AMPK) through increases in the (AMP):(ADP) ratio (13).

In hepatocytes and tumor cells, metformin can induce energetic stress $(86,87)$ by acting directly on mitochondria to inhibit the complex I-dependent respiration. In detail, metformin can suppress the energy transduction by selectively inducing a state in complex-I where redox and proton transfer domains are no longer efficiently coupled (88). The relevance of the inhibitory activity of metformin on the complex I-dependent respiration is still controversial because metformin did not really affect the cellular energy charge as expressed by the ATP:ADP ratio in some cell types $(87,89)$. In fact, metformin was shown to increase the energy formation in skeletal muscle cells and this finding was interpreted as consistent with its wellknown stimulatory effect on fatty acid oxidation (89). Moreover, the authors showed that metformin increased free AMP and ADP concentrations without affecting the ATP content and drew the conclusion that metformin can act as an AMP-deaminase inhibitor in skeletal muscle cells.

Mitochondrial glycerophosphate dehydrogenase (mGPDH) is a metformin target responsible for the gluconeogenesis inhibition in hepatocytes. MGPDH is a respiratory chain dehydrogenase, and its inhibition blocks the glycerophosphate shuttle, causing accumulation of cytosolic NADH and preventing glycerol and lactate from contributing to gluconeogenesis. Indeed, by inhibiting mGPDH, metformin elicited a significant increase in the cytosolic redox state and a decrease of the mitochondrial redox state in liver (87). mGPDH has also been shown to regulate thyroid cancer cell growth and metabolism. The overexpression of mGPDH was related to an increase of growth rate and oxidative phosphorylation and to higher sensitivity of thyroid cancer cell lines to the antiproliferative effects of metformin (90).

Finally, metformin indirectly targets different intracellular signalling pathways regulating protein synthesis, cell growth and differentiation, cell cycle progression and cell death. AMPK activation plays a central role in the effects of metformin on cell signalling but also AMPK-independent effects have been shown (12, $13,16,91,92)$. In the last decade, preclinical studies have accumulated that report on the possible role of metformin as an adjuvant agent in the medical treatment of pituitary adenomas (16). 


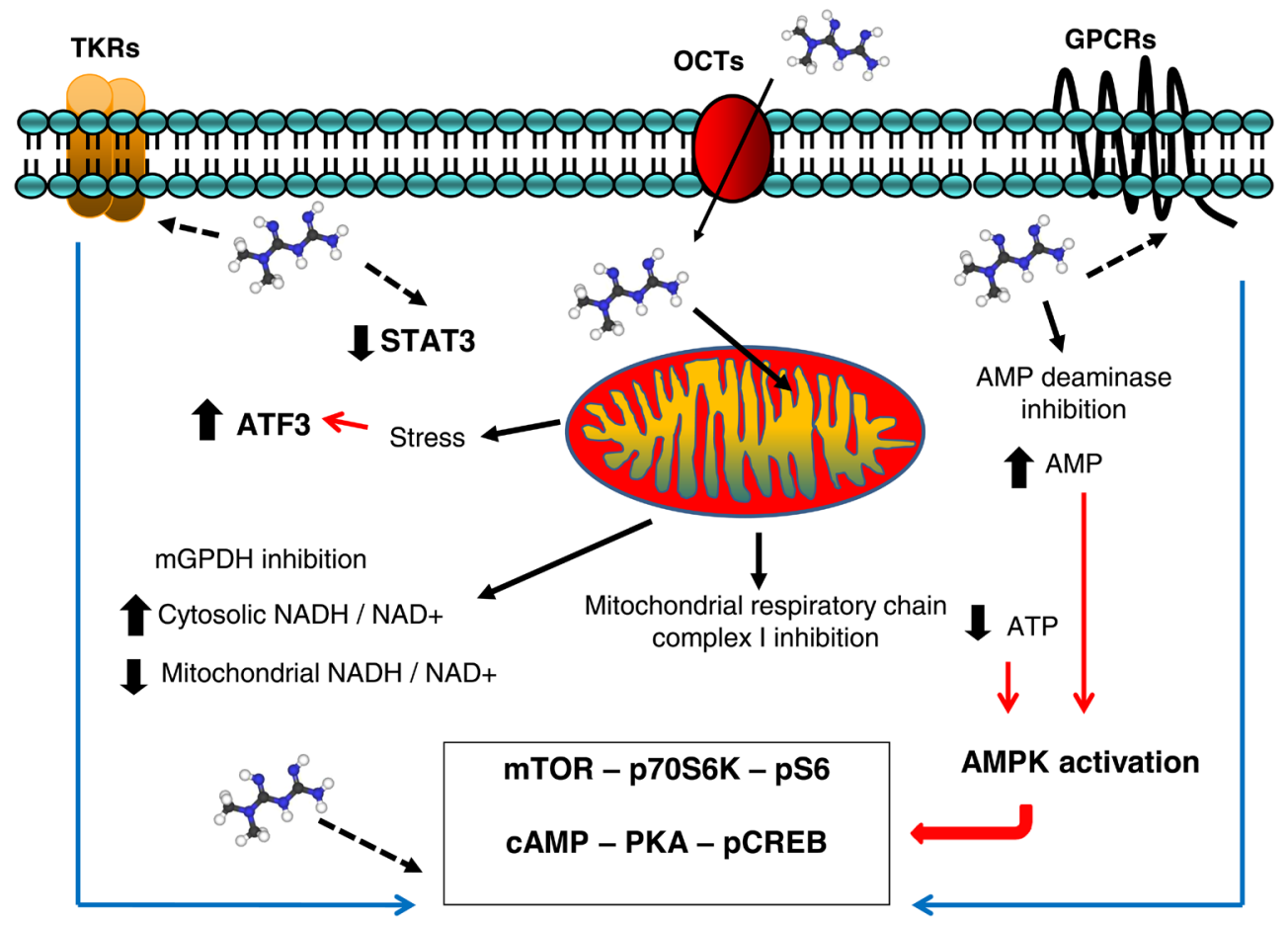

Figure 1

Actions of metformin in eukaryotic cells. Metformin needs to be transported into cells by transporters for cationic compound like organic cation transporters (OCTs). Then, according to reports, metformin has the potential to affect cell metabolism and cell signalling $(13,14)$. In fact, multiple activities have been described in normal and tumor cells. Metformin can induce energetic stress by inhibiting complex I (13) and mitochondrial glycerophosphate dehydrogenase (mGPDH) $(87,90)$. Metformin-mediated inhibition of mitochondrial respiration leads to oxidative stress which in turn can enhance the activity of the transcription factor ATF3, as observed in rat pituitary tumor cells (91). At the same time, the decrease of ATP levels can lead to the activation of AMP-activated protein kinase signalling (AMPK). AMPK activation is believed to mediate some stimulatory or inhibitory effects of metformin on different signalling pathways downstream of cell-surface receptors which, in turn, regulate cell growth and differentiation, programmed cell death, protein synthesis in normal- and tumor cells $(12,13,15)$, including pituitary tumor cells $(27)$. In skeletal muscle cells, metformin can activate AMPK through the inhibition of AMP deaminase, in the absence of significant changes in ATP levels (89). AMPK-independent effects of metformin on cell signalling have been also shown. The underlying mechanisms of action have not been fully described. In pituitary tumor cells, metformin inhibited STAT3 signalling (91). In normal primate pituitary cells, the effects of metformin on pituitary hormone secretion were found to be dependent on PI3K-mTOR pathway activation. Morover, the drug was able to increase the expression of G-protein-coupled receptors (GPCRs) (i.e. somatostatin receptors) and tyrosine-kinase receptors (TRKs) (i.e. insulin and IGF-1 receptors) in the same cells (46). See related text paragraph for details.

Pituitary adenomas are usually benign intracranial tumors that can be classified as functional (secretory) or non-functional tumors and categorized based on their mass (micro- or macroadenomas) and the specific pituitary hormone that they release. Most common pituitary adenomas include non-functioning adenomas, prolactinomas, GH-secreting- and ACTH-secreting tumors. The treatment of pituitary adenomas is surgical treatment and/or medical treatment, depending on the type of tumor, to reduce tumor mass and to inhibit hormone hypersecretion $(93,94,95)$. Novel drug options may be helpful to improve the efficacy of medical therapy for recurring invasive macroadenomas and for tumor showing partial or total resistance to current approved treatments (96).

Our research group investigated the effects of the AMP analogue AICAR on GH-secreting pituitary tumor cells in vitro. The activation of AMPK reduced the growth and decreased the viability of rat pituitary tumor cells (GH1 and GH3 cell lines) and inhibited the mTOR-p70S6 kinase pathway $(70,72)$. Actually, primary cell cultures from a number of human $\mathrm{GH}$-secreting pituitary adenomas revealed to be less sensitive to the treatment with AICAR compared with rat cell lines, and in that a limited number of tumors showed a modest decrease of cell viability and/or GH release and could be considered as responsive to AICAR (71). It is worth remarking that AICAR activated AMPK signalling in rat pituitary adenoma cells and human adenoma cells, including the adenomas that were classified as not responsive to AICAR. In conclusion, these data suggest to further explore factors that make some GH-secreting tumor cells responsive to an AMPK activator. These factors may include proliferation rate, activation of mTOR pathway downstream of cell surface growth 
factor receptors, basal AMPK activity and differences in cellular bioenergetics.

Multiple studies have examined the effects of metformin on growth and viability of pituitary adenoma cells in vitro. Metformin decreased cell proliferation and cell viability in AtT20 cells (ACTH-secreting mouse corticotroph cell line) (97), GH3- and GH1 cells (GH/PRLsecreting and GH-secreting cells, respectively) $(27,91)$. Moreover, metformin tended to suppress the release of GH and ACTH from GH3 cells and AtT20 cells, respectively $(91,97)$. As to the underlying cell signalling pathways, metformin activated AMPK in both AtT20 cells and GH3 cells $(27,97)$. In AtT20 cells, the drug inhibited the IGF-1R/ AKT/mTOR pathway. In GH3 cells, metformin was able to suppress the mTOR/p70S6 Kinase pathway. In this regard, it selectively modulated the signalling downstream of EGF receptor. Indeed, metformin reduced the p70S6 Kinase-mediated phosphorylation of S6 ribosomal protein without affecting ERK1/2 phosphorylation induced by EGF, at the same time (27). In a distinct study, an AMPKindependent mechanism of action of metformin in GH3 cells has been also suggested. The growth inhibitory effect was associated with increased activity of ATF3, a transcription factor induced by stress conditions (i.e. oxidative stress), and STAT3 inhibition (91).

Some issues need to be highlighted in the results of the previously discussed studies. AICAR-mediated activation of AMPK has been shown to increase the expression of the ACTH precursor, POMC in AtT20 cells (79). These data argue against an involvement of AMPK in the inhibitory action of metformin on ACTH production in the same cells. Furthermore, in contrast to AICAR, metformin did not induce apoptosis of GH3 cells when used in the same experimental conditions (27). We might conclude that the action of metformin is complex and does not entirely match the activity of a specific AMPK activator. Finally, it is worth adding that, in fact, a proapoptotic ATF3mediated effect of metformin was shown in GH3 cells (91). Some differences in the experimental conditions may at least partially account for the discrepancy between the two cited studies, that is, the duration of treatments.

The results of the studies examining the effects of metformin on human pituitary adenoma cells are more controversial and still limited. An and coworkers showed that metformin significantly suppressed cellular proliferation and $\mathrm{GH}$ secretion in primary human GH-secreting adenoma cells (91). Seven out of eight tumors were sensitive to the drug. More recently, Vazquez-Borrego and coworkers reported on the effects of three distinct biguanides on different types of pituitary tumors. Metformin treatment was shown to inhibit cell viability in human ACTH-secreting adenomas and non-functioning adenomas but not in GH-secreting and PRL-secreting tumors in vitro. Moreover, metformin did not affect ACTH, GH and prolactin secretion, although a higher concentration was used $(10 \mathrm{mM})$ compared with the previous cited study. Combined treatments with metformin and a somatostatin analogue were not more effective than somatostatin analogue monotherapy (92). In the same study, phenformin, which is not used clinically due to higher risk of lactic acidosis, was more effective than metformin and reduced cell viability in all pituitary adenomas. Moreover, it tended to decrease GH secretion and PRL secretion, not ACTH secretion. Finally, a preclinical study and case reports (two patients) have suggested that a combined treatment with metformin and bromocriptine may be effective at controlling hormone secretion and tumor growth in patients with prolactinomas resistant to bromocriptine (82). The authors also analyzed AMPK activation in surgical specimens of bromocriptine (BC)resistant- and BC-sensitive adenomas from patients treated for 3 months with the dopamine agonist. AMPK phosphorylation was high in specimens from BC-sensitive tumors and significantly suppressed in BC-resistant tumors. According to the authors, these data support an involvement of AMPK in regulating tumor growth and tumor cell response to the dopamine agonist (98). Actually, it is not possible to draw a clear conclusion. The different levels of AMPK activation may be the outcome of an uncontrolled hyperprolactinemia in patients with tumors resistant to the medical therapy compared with patients responsive to the drug in the months before surgery.

In conclusion, metformin have showed anti-tumor activity in different in vitro pituitary tumor models. This activity is mediated by both AMPK-dependent and AMPK-independent mechanisms. As to the translational relevance of the preclinical studies, there are some limitations (16).

Controversial results have been reported when human primary cells have been used. Taking also the effects on rat tumor cell lines into account, we may suggest that the proliferation rate could play a main role in determining the tumor cell response to the drug.

Metformin has revealed to be effective in vitro at concentrations ranging from 10(-5) to $10(-4) \mathrm{M}$. Based on the plasma levels of metformin in patients using the drug to treat type 2 diabetes, these concentrations are surely supra-therapeutic and could be toxic.

This work is licensed under a Creative Commons Attribution-NonCommercial-NoDerivatives 4.0 Internationab bicense.ifica .com at 04/26/2023 12:06:04PM 


\section{Final remarks}

AMPK has long been considered a drug target for the treatment of a variety of diseases due to its role of master energy sensor at cellular level and its well-recognized involvement in the regulation of a wide range of metabolic processes. Actually, the regulation of whole-body energy balance is complex and AMPK is not the only energy sensor working within cells. To this end, we may cite silent mating type information regulation 2 homolog 1 (SIRT1). SIRT1 is a NAD-dependent deacetylase regulating gene expression and protein activity. SIRT1 is a nutrient/redox sensor and has been recognized to exert an important role in energy balance both in the CNS and in peripheral tissues (99). Further complexity ensues from AMPK structure. AMPK is a heterotrimeric enzyme assembled in at least 12 isoforms from variable combinations of its subunits. These isoforms may differ with respect to specific activity for distinct substrates, sensitivity to dephosphorylation and activation by distinct endogenous- or synthetic ligands $(11,12)$. Based on these premises and the availability of recently developed activators targeting a different part of the AMPK molecule (12), extending preclinical investigations to the effects of these compounds could be helpful to ascertain the actual relevance of AMPK in the interplay between the activity of neuroendocrine axes and energy homeostasis at the hypothalamic and pituitary levels. AMPK inhibitory compounds would also be required to this purpose but the selectivity of currently available molecules is questionable.

Finally, as it has been done in different kind of tumors, it may be helpful to investigate the primary effects of metformin on cellular bioenergetics in pituitary tumor cells. The use of metformin may contribute to elucidate differences, if any, in metabolic requirements between pituitary adenomatous cells and normal cells.

\section{Declaration of interest}

The author declares that there is no conflict of interest that could be perceived as prejudicing the impartiality of this review.

\section{Funding}

It was supported by local funds from the Department of Molecular and Translational Medicine, University of Brescia to G T.

\section{References}

1 Melmed S \& Kleinberg D. Anterior pituitary. In Williams Textbook of Endocrinology, 11th ed., pp 155-261. Eds HM Kronenberg, S Melmed, KS Polonsky \& PR Larsen. Amsterdam, Netherlands: Saunders Elsevier, 2008.
2 Musumeci G, Castorina S, Castrogiovanni P, Loreto C, Leonardi R, Aiello FC, Magro G \& Imbesi R. A journey through the pituitary gland: development, structure and function, with emphasis on embryo-fetal and later development. Acta Histochemica 2015117 355-366. (https://doi.org/10.1016/j.acthis.2015.02.008)

3 Murray PG, Higham CE \& Clayton PE. The hypothalamo-GH axis: the past 60 years. Journal of Endocrinology 201526 T123-T140.

4 Vazquez-Borrego MC, Gahete MD, Martínez-Fuentes AJ, FuentesFayos AC, Castano JP, Kineman RD \& Luque RM. Multiple signaling pathways convey central and peripheral signals to regulate pituitary function: lessons from human and non-human primate models. Molecular and Cellular Endocrinology 2018463 4-22. (https://doi. org/10.1016/j.mce.2017.12.007)

5 Duval DL. PRKA/AMPK: integrating energy status with fertility in pituitary gonadotrophs. Biology of Reproduction 201184 205-206. (https://doi.org/10.1095/biolreprod.110.089722)

6 Tulipano G, Faggi L, Sibilia V \& Giustina A. Points of integration between the intracellular energy sensor AMP-activated protein kinase (AMPK) activity and the somatotroph axis function. Endocrine 2012 42 292-298. (https://doi.org/10.1007/s12020-012-9732-x)

7 Sarmento-Cabral A, Peinado JR, Halliday LC, Malagon MM, Castaño JP, Kineman RD \& Luque RM. Adipokines (leptin, adiponectin, resistin) differentially regulate all hormonal cell types in primary anterior pituitary cell cultures from two primate species. Scientific Reports 20177 43537. (https://doi.org/10.1038/ srep43537)

8 Hardie DG. AMP-activated/SNF1 protein kinases: conserved guardians of cellular energy. Nature Reviews: Molecular Cell Biology 20078 774-785. (https://doi.org/10.1038/nrm2249)

9 Lim CT, Kola B \& Korbonits M. AMPK as a mediator of hormonal signalling. Journal of Molecular Endocrinology 201044 87-97. (https:// doi.org/10.1677/JME-09-0063)

10 Wang B \& Cheng KK. Hypothalamic AMPK as a mediator of hormonal regulation of energy balance. International Journal of Molecular Sciences 201819 3552. (https://doi.org/10.3390/ ijms19113552)

11 López M, Nogueiras R, Tena-Sempere M \& Diéguez C. Hypothalamic AMPK: a canonical regulator of whole-body energy balance. Nature Reviews: Endocrinology 201612 421-432. (https://doi.org/10.1038/ nrendo.2016.67)

12 Neumann D \& Viollet B. AMP-acivated protein kinase signalling. International Journal of Molecular Sciences 201920 766. (https://doi. org/10.3390/ijms20030766)

13 Viollet B, Guigas B, Sanz Garcia N, Leclerc J, Foretz M \& Andreelli F. Cellular and molecular mechanisms of metformin: an overview. Clinical Science 2012122 253-270. (https://doi.org/10.1042/ CS20110386)

14 Evans JM, Donnelly LA, Emslie-Smith AM, Alessi DR \& Morris AD. Metformin and reduced risk of cancer in diabetic patients. BMJ 2005 330 1304-1305. (https://doi.org/10.1136/bmj.38415.708634.F7)

15 Motoshima H, Goldstein BJ, Igata M \& Araki E. AMPK and cell proliferation - AMPK as a therapeutic target for atherosclerosis and cancer. Journal of Physiology 2006574 63-71. (https://doi. org/10.1113/jphysiol.2006.108324)

16 Thakur S, Daley B \& Klubo-Gwiezdzinska J. The role of the antidiabetic drug metformin in the treatment of endocrine tumors. Journal of Molecular Endocrinology 201963 R17-R35. (https://doi. org/10.1530/JME-19-0083)

17 Towler MC \& Hardie DG. AMP-activated protein kinase in metabolic control and insulin signaling. Circulation Research $2007100328-341$. (https://doi.org/10.1161/01.RES.0000256090.42690.05)

18 Locatelli V \& Torsello A. Pyruvate and satiety: can we fool the brain? Endocrinology 2005146 1-2. (https://doi.org/10.1210/en.2004-1336)

19 McCarty MF. Chronic activation of AMP-activated kinase as a strategy for slowing aging. Medical Hypotheses 200463 334-339. (https://doi.org/10.1016/j.mehy.2004.01.043) 
20 Steinberg GR \& Jorgensen SB. The AMP-activated protein kinase: role in regulation of skeletal muscle metabolism and insulin sensitivity. Mini Reviews in Medicinal Chemistry 20077 519-526. (https://doi. org/10.2174/138955707780619662)

21 Rattan R, Giri S, Singh AK \& Singh I. 5-Aminoimidazole-4-carbox amide-1-beta-D-ribofuranoside inhibits cancer cell proliferation in vitro and in vivo via AMP-activated protein kinase. Journal of Biological Chemistry 2005280 39582-39593. (https://doi. org/10.1074/jbc.M507443200)

22 Zakikhani M, Dowling R, Fantus IG, Sonenberg N \& Pollak M. Metformin is an AMP kinase-dependent growth inhibitor for breast cancer cells. Cancer Research 200666 10269-10273. (https://doi. org/10.1158/0008-5472.CAN-06-1500)

23 Gao Y, Zhou Y, Xu A \& Wu D. Effects of an AMP-activated protein kinase inhibitor, compound $\mathrm{C}$, on adipogenic differentiation of 3T3L1 cells. Biological and Pharmaceutical Bulletin 200831 1716-1722. (https://doi.org/10.1248/bpb.31.1716)

24 Kanazawa I, Yamaguchi T, Yano S, Yamauchi M \& Sugimoto T. Activation of AMP kinase and inhibition of Rho kinase induce the mineralization of osteoblastic MC3T3E1 cells through endothelial NOS and BMP-2 expression. American Journal of Physiology: Endocrinology and Metabolism 2009296 E139-E146. (https://doi. org/10.1152/ajpendo.90677.2008)

25 Mihaylova MM \& Shaw RJ. The AMPK signalling pathway coordinates cell growth, autophagy and metabolism. Nature Cell Biology 201113 1016-1023. (https://doi.org/10.1038/ncb2329)

26 Park HU, Suy S, Danner M, Dailey V, Zhang Y, Li H, Hyduke DR, Collins BT, Gagnon G, Kallakury B, et al. AMP-activated protein kinase promotes human prostate cancer cell growth and survival. Molecular Cancer Therapeutics 20098 733-741. (https://doi. org/10.1158/1535-7163.MCT-08-0631)

27 Faggi L, Giustina A \& Tulipano G. Effects of metformin on cell growth and AMPK activity in pituitary adenoma cell cultures, focusing on the interaction with adenylyl cyclase activating signals. Molecular and Cellular Endocrinology 2018470 60-74. (https://doi. org/10.1016/j.mce.2017.09.030)

28 Horike N, Sakoda H, Kushiyama A, Ono H, Fujishiro M, Kamata H, Nishiyama K, Uchijima Y, Kurihara Y, Kurihara H, et al. AMPactivated protein kinase activation increases phosphorylation of glycogen synthase kinase 3 beta and thereby reduces cAMP-responsive element transcriptional activity and phosphoenol-pyruvate carboxykinase C gene expression in the liver. Journal of Biological Chemistry 2008283 33902-33910. (https://doi.org/10.1074/jbc.M802537200)

29 Miller RA, Chu Q, Xie J, Foretz M, Viollet B \& Birnbaum MJ. Biguanides suppress glucagone signalling by decreasing production of cyclicAMP. Nature 2013494 256-260. (https://doi.org/10.1038/ nature11808)

30 Thomson DM, Herway ST, Fillmore N, Kim H, Brown JD, Barrow JR \& Winder WW. AMP-activated protein kinase phosphorylates transcription factors of the CREB family. Journal of Applied Physiology 2008104 429-438. (https://doi.org/10.1152/ japplphysiol.00900.2007)

31 Didier S, Sauve F, Domise M, Buee L, Marinangeli C \& Vingtdeux V. AMP-activated protein kinase controls immediate early genes expression following synaptic activation through the pka/creb pathway. International Journal of Molecular Sciences 201819 E3716. (https://doi.org/10.3390/ijms19123716)

32 Navarro VM \& Kaiser UB. Metabolic influences on neuroendocrine regulation of reproduction. Current Opinion in Endocrinology, Diabetes, and Obesity 201320 335-341. (https://doi.org/10.1097/ MED.0b013e32836318ce)

33 Krsmanovic LZ, Hu L, Leung PK, Feng H \& Catt KJ. The hypothalamic GnRH pulse generator: multipleregulatory mechanisms. Trends in Endocrinology and Metabolism 200920 402-408. (https://doi.org/10.1016/j.tem.2009.05.002)
34 Kotani M, Detheux M, Vandenbogaerde A, Communi D, Vanderwinden JM, Le Poul E, Brézillon S, Tyldesley R, SuarezHuerta N, Vandeput F, et al. The metastasis suppressor gene KiSS-1 encodes kisspeptins, the natural ligands of the orphan $G$ proteincoupled receptor GPR54. Journal of Biological Chemistry 2001276 34631-34636. (https://doi.org/10.1074/jbc.M104847200)

35 Muir AI, Chamberlain L, Elshourbagy NA, Michalovich D, Moore DJ, Calamari A, Szekeres PG, Sarau HM, Chambers JK, Murdock P, et al. AXOR12, a novel human $G$ protein-coupled receptor, activated by the peptide KiSS-1. Journal of Biological Chemistry 2001276 28969-28975. (https://doi.org/10.1074/jbc.M102743200)

36 Ohtaki T, Shintani Y, Honda S, Matsumoto H, Hori A, Kanehashi K, Terao Y, Kumano S, Takatsu Y, Masuda Y, et al. Metastasis suppressor gene KiSS-1 encodes peptide ligand of a G-protein-coupled receptor. Nature 2001411 613-617. (https://doi.org/10.1038/35079135)

37 Stafford LJ, Xia C, Ma W, Cai Y \& Liu M. Identification and characterization of mouse metastasis suppressor KiSS1 and its G-protein-coupled receptor. Cancer Research 200262 5399-5404.

38 Pinilla L, Aguilar E, Dieguez C, Millar RP \& Tena-Sempere M. Kisspeptins and reproduction: physiological roles and regulatory mechanisms. Physiological Reviews 201292 1235-1316. (https://doi. org/10.1152/physrev.00037.2010)

39 Navarro VM. New insights into the control of pulsatile GnRH release: the role of Kiss1/neurokinin B neurons. Frontiers in Endocrinology 20123 48. (https://doi.org/10.3389/fendo.2012.00048)

40 Roa J, Barroso A, Ruiz-Pino F, Vázquez MJ, Seoane-Collazo P, Martínez-Sanchez N, García-Galiano D, Ilhan T, Pineda R, León S, et al. Metabolic regulation of female puberty via hypothalamic AMPK-kisspeptin signalling. PNAS 2018115 E10758-E10767. (https://doi.org/10.1073/pnas.1802053115)

41 Ibanez L, Lopez-Bermejo A, Diaz M, Marcos MV \& de Zegher F. Early metformin therapy to delay menarche and augment height in girls with precocious pubarche. Fertility and Sterility 201195 727-730. (https://doi.org/10.1016/j.fertnstert.2010.08.052)

42 Ibánez L, López-Bermejo A, Díaz M, Marcos MV \& de Zegher F. Early metformin therapy (age 8-12 years) in girls with precocious pubarche to reduce hirsutism, androgen excess, and oligomenorrhea in adolescence. Journal of Clinical Endocrinology and Metabolism 2011 96 E1262-E1267. (https://doi.org/10.1210/jc.2011-0555)

43 Shakya M, Shrestha PK \& Briski KP. Hindbrain 5'AMP-activated protein kinase mediates short-term food deprivation inhibition of the GnRH-LH axis: role of nitric oxide. Neuroscience 2018383 46-59. (https://doi.org/10.1016/j.neuroscience.2018.04.040)

44 Tosca L, Froment P, Rame C, McNeilly JR, McNeilly AS, Maillard V \& Dupont J. Metformin decreases GnRH- and activin-induced gonadotropin secretion in rat pituitary cells: potential involvement of AMP-activated kinase (AMPK). Biology of Reproduction 201184 351-362. (https://doi.org/10.1095/biolreprod.110.087023)

45 Lu M, Tang Q, Olefsky JM, Mellon PL \& Webster NJ. Adiponectin activates AMP-activated protein kinase and decreases LH secretion in L(b)T2 gonadotropes. Molecular Endocrinology 200822 760-771. (https://doi.org/10.1210/me.2007-0330)

46 Vázquez-Borrego MC, Fuentes-Fayosa AC, Gahetea MD, Castaño JP, Kinemane RD \& Luque RM. The pituitary gland is a novel major site of action of metformin in non-human primates: a potential path to expand and integrate its metabolic actions. Cellular Physiology and Biochemistry 201849 1444-1459. (https://doi. org/10.1159/000493448)

47 Giustina A \& Veldhuis JD. Pathophysiology of the neuroregulation of growth hormone secretion in experimental animals and the human. Endocrine Reviews 199819 717-797. (https://doi.org/10.1210/ edrv.19.6.0353)

48 Muller EE, Locatelli V \& Cocchi D. Neuroendocrine control of growth hormone secretion. Physiological Reviews 199979 511-607. (https://doi.org/10.1152/physrev.1999.79.2.511) https://ec.bioscientifica.com https://doi.org/10.1530/EC-19-0482 (c) 2020 The author Published by Bioscientifica Ltd
This work is licensed under a Creative Commons Attribution-NonCommercial-NoDerivatives 4.0 Internationab ticense.ifica com at $04 / 26 / 2023 \quad 12: 06: 04 \mathrm{PM}$ 
49 Gunther T, Tulipano G, Dournaud P, Bousquet C, Csaba Z, Kreienkamp HJ, Lupp A, Korbonits M, Castano JP, Wester HJ, et al. International Union of Basic and Clinical Pharmacology. CV. Somatostatin receptors: structure, function, ligands, and new nomenclature. Pharmacological Reviews 201870 763-835. (https:// doi.org/10.1124/pr.117.015388)

50 Kojima M, Hosoda H, Date Y, Nakazato M, Matsuo H \& Kangawa K. Ghrelin is a growth-hormone-releasing acylated peptide from stomach. Nature 1999402 656-660. (https://doi.org/10.1038/45230)

51 Camina JP, Carreira MC, Micic D, Pombo M, Kelestimur F, Dieguez C \& Casanueva FF. Regulation of ghrelin secretion and action. Endocrine 200322 5-12. (https://doi.org/10.1385/ENDO:22:1:5)

52 Solomou S \& Korbonitz M. The role of ghrelin in weight-regulation disorders: implications in clinical practice. Hormones 201413 458-475. (https://doi.org/10.14310/horm.2002.1551)

53 Baragli A, Lanfranco F, Allasia S, Granata R \& Ghigo E. Neuroendocrine and metabolic activities of ghrelin gene products. Peptides 201132 2323-2332. (https://doi.org/10.1016/j. peptides.2011.10.024)

54 Sun Y, Ahmed S \& Smith RG. Deletion of ghrelin impairs neither growth nor appetite. Molecular and Cellular Biology 200323 7973-7981. (https://doi.org/10.1128/mcb.23.22.7973-7981.2003)

55 Ibáñez-Costa A, Luque RM \& Castaño JP. Cortistatin: a new link between the growth hormone/prolactin axis, stress, and metabolism. Growth Hormone and IGF Research 201733 23-27. (https://doi. org/10.1016/j.ghir.2017.01.004)

56 Mazziotti G \& Giustina A. Glucocorticoids and the regulation of growth hormone secretion. Nature Reviews: Endocrinology 20139 265-276. (https://doi.org/10.1038/nrendo.2013.5)

57 Cornford AS, Barkan AL \& Horowitz JF. Rapid suppression of growth hormone concentration by overeating: potential mediation by hyperinsulinemia. Journal of Clinical Endocrinology and Metabolism 201196 824-830. (https://doi.org/10.1210/jc.2010-1895)

58 Lanzi R, Manzoni MF, Andreotti AC, Malighetti ME, Bianchi E, Sereni LP, Caumo A, Luzi L \& Pontiroli AE. Evidence for an inhibitory effect of physiological levels of insulin on the growth hormone (GH) response to GH-releasing hormone in healthy subjects. Journal of Clinical Endocrinology and Metabolism 199782 2239-2243. (https:// doi.org/10.1210/jcem.82.7.4071)

59 Luque RM, Gahete MD, Valentine RJ \& Kineman RD. Examination of the direct effects of metabolic factors on somatotrope function in a non-human primate model, Papio Anubis. Journal of Molecular Endocrinology 200637 25-38. (https://doi.org/10.1677/jme.1.02042)

60 Kalra SP, Dube MG, Pu S, Xu B, Horvath TL \& Kalra PS. Interacting appetite-regulating pathways in the hypothalamic regulation of body weight. Endocrine Reviews 199920 68-100. (https://doi.org/10.1210/ edrv.20.1.0357)

61 Perry RJ, Resch JM, Douglass AM, Madara JC, Rabin-Court A, Kucukdereli H, Wu C, Song JD, Lowell BB \& Shulman GI. Leptin's hunger-suppressing effects are mediated by the hypothalamic-pi tuitary-adrenocortical axis in rodents. PNAS 2019116 13670-13679. (https://doi.org/10.1073/pnas.1901795116)

62 Carro E, Senaris R, Considine RV, Casanueva FF \& Dieguez C. Regulation of in vivo growth hormone secretion by leptin. Endocrinology 1997138 2203-2206. (https://doi.org/10.1210/ endo.138.5.5238)

63 Cocchi D, De Gennaro Colonna V, Bagnasco M, Bonacci D \& Muller EE. Leptin regulates $\mathrm{GH}$ secretion in the rat by acting on GHRH and somatostatinergic functions. Journal of Endocrinology 1999 162 95-99. (https://doi.org/10.1677/joe.0.1620095)

64 Baratta M, Saleri R, Mainardi GL, Valle D, Giustina A \& Tamanini C. Leptin regulates $\mathrm{GH}$ gene expression and secretion and nitric oxide production in pig pituitary cells. Endocrinology 2002143 551-557. (https://doi.org/10.1210/endo.143.2.8653)

65 Sahu A. Leptin signalling in the hypothalamus: emphasis on energy homeostasis and leptin resistance. Frontiers in Neuroendocrinology 200424 225-253.
66 Tulipano G, Vergoni AV, Soldi D, Muller EE \& Cocchi D. Characterization of the resistance to the anorectic and endocrine effects of leptin in obesity-prone and obesity-resistant rats fed a high-fat diet. Journal of Endocrinology 2004183 289-298. (https://doi. org/10.1677/joe.1.05819)

67 Ozata M, Dieguez C \& Casanueva FF. The inhibition of growth hormone secretion presented in obesity is not mediated by the high leptin levels: a study in human leptin deficiency patients. Journal of Clinical Endocrinology and Metabolism 200388 312-316. (https://doi. org/10.1210/jc.2002-020122)

68 Weyer C, Funahashi T, Tanaka S, Hotta K, Matsuzawa Y, Pratley RE \& Tataranni PA. Hypoadiponectinemia in obesity and type 2 diabetes: close association with insulin resistance and hyperinsulinemia. Journal of Clinical Endocrinology and Metabolism 200186 1930-1935. (https://doi.org/10.1210/jcem.86.5.7463)

69 Nilsson L, Binart N, Bohlooly M, Bramnert M, Egecioglu E, Kindblom J,Kelly PA, Kopchick JJ, Ormandy CJ, Ling C, et al. Prolactin and growth hormone regulate adiponectin secretion and receptor expression in adipose tissue. Biochemical and Biophysical Research Communications 2005331 1120-1126. (https://doi. org/10.1016/j.bbrc.2005.04.026)

70 Tulipano G, Giovannini M, Spinello M, Sibilia V, Giustina A \& Cocchi D. AMP-activated protein kinase regulates normal rat somatotroph cell function and growth of rat pituitary adenomatous cells. Pituitary 201114 242-252. (https://doi.org/10.1007/s11102010-0288-6)

71 Tulipano G, Faggi L, Losa M, Mortini P, Spinello M, Sibilia V, Pagani F, Cocchi D \& Giustina A. Effects of AMPK activation and combined treatment with AMPK activators and somatostatin on hormone secretion and cell growth in cultured GH-secreting pituitary tumor cells. Molecular and Cellular Endocrinology 2013365 197-206. (https://doi.org/10.1016/j.mce.2012.10.017)

72 Tulipano G, Faggi L, Cacciamali A, Spinello M, Cocchi D \& Giustina A. Role of AMP-activated protein kinase (AMPK) activators in antiproliferative multidrug pituitary tumor therapies: effects of combined treatments with compounds affecting the mTORp70S6 kinase axis in cultured pituitary tumour cells. Journal of Neuroendocrinology 201527 20-32. (https://doi.org/10.1111/jne.12231)

73 Pollak M. Insulin and insulin-like growth factor signalling in neoplasia. Nature Reviews: Cancer 20088 915-928. (https://doi. org/10.1038/nrc2536)

74 Foretz M, Guigas B, Bertrand L, Pollak M \& Viollet B. Metformin: from mechanisms of action to therapies. Cell Metabolism 201420 953-966. (https://doi.org/10.1016/j.cmet.2014.09.018)

75 Schatz H, Doci S \& Hofer R. The effect of dimethylbiguanide on glucose tolerance, serum insulin and growth hormone in obese patients. Diabetologia 19728 1-7. (https://doi.org/10.1007/bf01219979)

76 Guido M, Romualdi D, Giuliani M, Suriano R, Tienforti D, Costantini B \& Lanzone A. Effect of metformin on the growth hormone response to growth hormone-releasing hormone in obese women with polycystic ovary syndrome. Fertility and Sterility $2005 \mathbf{8 4}$ 1470-1476. (https://doi.org/10.1016/j.fertnstert.2005.05.027)

77 Longo VD, Antebi A, Bartke A, Barzilai N, Brown-Borg HM, Caruso C, Curiel TJ, de Cabo R, Franceschi C, Gems D, et al. Interventions to slow aging in humans: are we ready? Aging Cell 201514 497-510. (https://doi.org/10.1111/acel.12338)

78 Bartke A. Growth hormone and aging: updated review. World Journal of Men's Health 201937 19-30. (https://doi.org/10.5534/ wjmh.180018)

79 Iwasaki Y, Nishiyama M, Taguchi T, Kambayashi M, Asai M, Yoshida M, Nigawara T \& Hashimoto K. Activation of AMP-activated protein kinase stimulates proopiomelanocortin gene transcription in AtT20 corticotroph cells. American Journal of Physiology: Endocrinology and Metabolism 2007292 E1899-E1905. (https://doi.org/10.1152/ ajpendo.00116.2006)

80 Chen M, Wang Z, Zhan M, Liu R, Nie A, Wang J, Ning G \& Ma Q, Adiponectin regulates ACTH secretion and the HPAA in an AMPK- 
dependent manner in pituitary corticotroph cells. Molecular and Cellular Endocrinology 2014383 118-125. (https://doi.org/10.1016/j. mce.2013.12.007)

81 Psilopanagioti A, Papadaki H, Kranioti EF, Alexandrides TK \& Varakis JN, Expression of adiponectin and diponectin receptors in human pituitary gland and brain. Neuroendocrinology 200989 38-47. (https://doi.org/10.1159/000151396)

82 Liu X, Liu Y, Gao J, Feng M, Bao X, Deng K, Yao Y \& Wang R. Combination treatment with bromocriptine and metformin in patients with bromocriptine-resistant prolactinomas: pilot study. World Neurosurgery 2018115 94-98. (https://doi.org/10.1016/j. wneu.2018.02.188)

83 Krysiak R, Szkróbka W \& Okopień B. Sex-dependent effect of metformin on serum prolactin levels in hyperprolactinemic patients with type 2 diabetes: a pilot study. Experimental and Clinical Endocrinology and Diabetes 2018126 342-348. (https://doi. org/10.1055/s-0043-122224)

84 Gallagher EJ \& LeRoith D. Diabetes, cancer, and metformin: connections of metabolism and cell proliferation. Annals of the New York Academy of Sciences 20111243 54-68. (https://doi.org/10.1111/ j.1749-6632.2011.06285.x)

85 Schulten HJ. Pleiotropic effects of metformin on cancer. International Journal of Molecular Sciences 201819 E2850. (https://doi.org/10.3390/ ijms19102850)

86 Andrzejewski S, Gravel SP, Pollak M \& St-Pierre J. Metformin directly acts on mitochondria to alter cellular bioenergetics. Cancer and Metabolism 20142 12. (https://doi.org/10.1186/2049-3002-2-12)

87 Madiraju AK, Erion DM, Rahimi Y, Zhang XM, Braddock DT, Albright RA, Prigaro BJ, Wood JL, Bhanot S, MacDonald MJ, et al. Metformin suppresses gluconeogenesis by inhibiting mitochondrial glycerophosphate dehydrogenase. Nature 2014510 542-546. (https://doi.org/10.1038/nature13270)

88 Cameron AR, Logie L, Patel K, Erhardt S, Bacon S, Middleton P, Harthill J, Forteath C, Coats JT, Kerra C, et al. Metformin selectively targets redox control of complex I energy transduction. Redox Biology 201814 187-197. (https://doi.org/10.1016/j.redox.2017.08.018)

89 Vytla VS \& Ochs RS. Metformin increases mitochondrial energy formation in L6 muscle cell cultures. Journal of Biological Chemistry 2013288 20369-20377. (https://doi.org/10.1074/jbc.M113.482646)

90 Thakur S, Daley B, Gaskins K, Vasko VV, Boufraqech M, Patel D, Sourbier C, Reece J, Cheng SY, Kebebew E, et al. Metformin targets mitochondrial glycerophosphate dehydrogenase (mGPDH) to control rate of oxidative phosphorylation and growth of thyroid cancer in vitro and in vivo. Clinical Cancer Research 201824 4030-4043. (https://doi.org/10.1158/1078-0432.CCR-17-3167)

91 An J, Pei X, Zang Z, Zhou Z, Hu J, Zheng X, Zhang Y, He J, Duan L, Shen $\mathrm{R}$, et al. Metformin inhibits proliferation and growth hormone secretion of GH3 pituitary adenoma cells. Oncotarget 20178 37538-37549. (https://doi.org/10.18632/oncotarget.16556)

92 Vázquez-Borrego MC, Fuentes-Fayos AC, Herrera-Martínez AD, L-López F, Ibánez-Costa A, Moreno-Moreno P, AlhambraExpósito MR, Barrera-Martín A, Blanco-Acevedo C, Dios E, et al. Biguanides exert antitumoral actions in pituitary tumor cells through AMPK-dependent and -independent mechanisms. Journal of Clinical Endocrinology and Metabolism 2019104 3501-3513.

93 Theodros D, Patel M, Ruzevick J, Lim M \& Bettegowda C. Pituitary adenomas: historical perspective, surgical management and future directions. CNS Oncology 20154 411-429. (https://doi.org/10.2217/ cns.15.21)

94 Giustina A, Mazziotti G, Torri V, Spinello M, Floriani I \& Melmed S. Metanalysis on the effects of octreotide on tumor mass in acromegaly. PLoS ONE 20127 e36411. (https://doi.org/10.1371/ journal.pone.0036411)

95 Giustina A, Bevan JS, Bronstein MD, Casanueva FF, Chanson P, Petersenn S, Thanh XM, Sert C, Houchard A, Guillemin I, et al. SAGIT®: Clinician-reported outcome instrument for managing acromegaly in clinical practice-development and results from a pilot study. Pituitary 201619 39-49. (https://doi.org/10.1007/s11102-015-0681-2)

96 Gola M, Bonadonna S, Mazziotti G, Amato G \& Giustina A. Resistance to somatostatin analogs in acromegaly: an evolving concept? Journal of Endocrinological Investigation 200629 86-93. (https://doi.org/10.1007/BF03349183)

97 Jin K, Ruan L, Pu J, Zhong A, Wang F, Tan S, Huang H, Mu J \& Yang G. Metformin suppresses growth and adrenocorticotrophic hormone secretion in mouse pituitary corticotroph tumor att20 cells. Molecular and Cellular Endocrinology 2018478 53-61. (https://doi. org/10.1016/j.mce.2018.07.007)

98 Gao J, Liu Y, Han G, Deng K, Liu X, Bao X, Feng M, Yao Y, Lian W, Xing B, et al. Metformin inhibits growth and prolactin secretion of pituitary prolactinoma cells and xenografts. Journal of Cellular and Molecular Medicine 201822 6368-6379. (https://doi.org/10.1111/ jcmm.13963)

99 Nillni EA. The metabolic sensor Sirt1 and the hypothalamus: inteplay between peptide hormones and pro-hormone covertases. Molecular and Cellular Endocrinology 2016438 77-88. (https://doi. org/10.1016/j.mce.2016.09.002)

Received in final form 16 December 2019

Accepted 1 January 2020

Accepted Manuscript published online 6 January 2020 https://ec.bioscientifica.com https://doi.org/10.1530/EC-19-0482 (c) 2020 The author Published by Bioscientifica Ltd
This work is licensed under a Creative Commons Attribution-NonCommercial-NoDerivatives 4.0 Internationab ticense ifica . com at 04/26/2023 12:06:04PM 